\title{
PROPERTIES OF THE FLUOTHANE-ETHER ANAESTHETIC ${ }^{1}$
}

\author{
Paul A. BoIvin, D.SC., ${ }^{2}$ F. Hudon, M.D., F.R.C.P.(c), F.F.A.R.C.S., ${ }^{3}$ \\ and A. JACQUES, M.D., F.R.C.P. (C) ${ }^{4}$
}

Physics AND CHEMIstRy may bring a. happy contribution to medicine in the study and the choice of anaesthetics, as will be illustrated by the study of the characteristics of a new compound, made up of Fluothane and ether.

When Fluothane and ether were mixed together, heat was produced. The temperature rose to about $33^{\circ} \mathrm{C}$. as Fluothane and ether passed into solution: this phenomenon is called heat of solution. This solution, which is produced with a decrease of volume due to the molecular attraction, is not an ideal solution.

In order to identify this mixture, the vapour pressure was determined and was found to be equal to $213.3 \mathrm{~mm}$. Hg for a temperature of $24^{\circ} \mathrm{C}$. while the vapour pressure of ether and Fluothane was respectively $442 \mathrm{~mm} . \mathrm{Hg}$ and $264 \mathrm{~mm}$. $\mathrm{Hg}$ for the same temperature. This showed us that the boiling point of the mixture should be slightly higher than that of Fluothane if an azeotropic compound had been discovered. An azeotropic compound is a mixture of two substances which distil at the same temperature.

By distilling a mixture composed of two parts of Flwothane and one part ether, the presence of an azeotropic compound was detected. This compound distils at a constant temperature of $51.5^{\circ} \mathrm{C}$. in definite proportions: 31.7 per cent ether and 68.3 per cent Fluothane.

When distilling $75 \mathrm{cc}$. of such mixture, a first $5 \mathrm{cc}$. fraction boiling between $50.5^{\circ} \mathrm{C}$. and $51.5^{\circ} \mathrm{C}$. was recovered. this fraction was composed of 33 per cent ether and 67 per cent Fluothane. Then the temperature was raised to $51.5^{\circ} \mathrm{C}$. and a second fraction of about 65 to $68 \mathrm{cc}$. of the azeotropic compound ( $31.7 \mathrm{per}$ cent ether for 68.3 per cent Fluothane) were separated out. Finally, the temperature was lowered to $50.2^{\circ} \mathrm{C}$. and a few drops of Fluothane were obtained.

When a mixture of 31.7 parts of ether and 68.3 parts Fluothane was boiled, it distilled at $51.5^{\circ} \mathrm{C}$.: this was the boiling point of the mixture.

When such a mixture was vaporized in the Boyle apparatus by means of a current of 50 per cent nitrous oxide, vapours were condensed in a trap coolec. by dry ice dissolved in acetone. As was expected, the mixture composition in the vapour phase remained the same as that in the liquid phase: 31.7 per cent ether and 68.3 per cent Fluothane. Analyses were made by determining densities by means of a precalibrated micropycnometer (Fig. 1).

Following these results other experiments were carried out. While a patient was being anaesthetized with this azeotropic mixture, the vapours produced by the expiration were condensed. The condensation products were water, ether, and Fluothane. After elimination of water, analyses proved that ether and Fluothane

${ }^{1}$ Contribution from the Departments of Biochemistry and Anaesthesia, Faculty of Medicine, Laval University, and the Hôtel-Dieu of Quebec Hospital, Quebec, P.Q.

2Department of Biochemistry, Faculty of Medicine, Laval University, Quebec, P.Q.

${ }^{3}$ Head of the Departments of Anzesthesia, Faculty of Medicine, Laval Unıversity, and Hôtel-Dieu of Quebec Hospital, Quebec, P.Q.

4Department of Anaesthesia, Hôtel-Dieu of Quebec Hospital, Quebec, P.Q. 


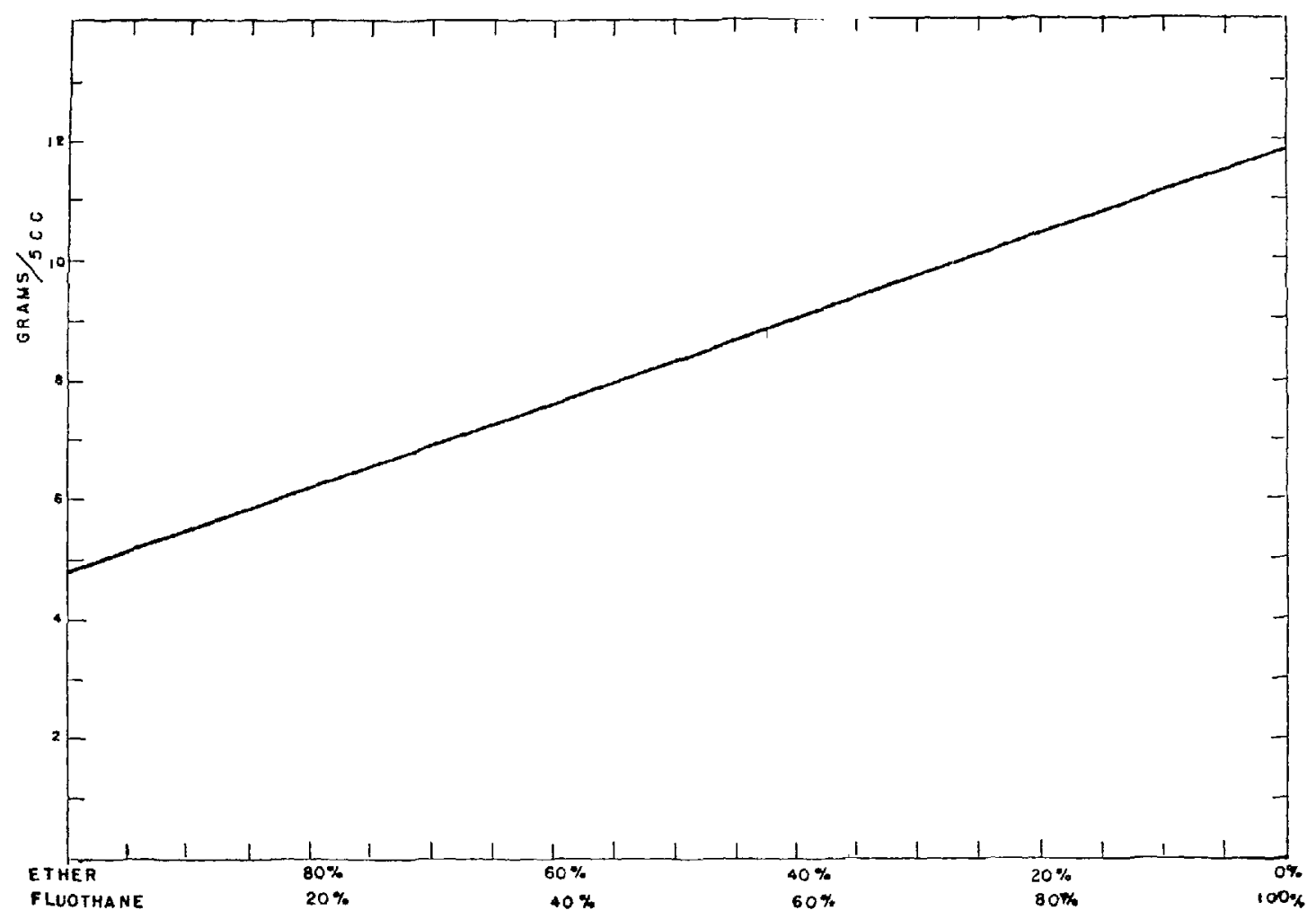

FIGUnE 1. Determination of the relative proportions of ether and Fluothane from the density of a mixture measured in a 5 cc. micropycnometer.

were always in their azeotropic proportions: 31.7 per cent ether and 68.3 per cent Fluothane. It was also interesting to know the proportion of free acids produced by some decomposition of the mixture in the organism. Analyses proved that fluorine was firmly bound in the molecule when the mixture is not exposed to light. Analyses of a mixture kept in the Boyle apparatus for 48 hours did not reveal the presence of fluorine as free acid. But there was formation of very small quantities of bromine or chlorine as free acids: the proportion exhaled by the patient was not more than one part per million, a quantity already existing in the mixture inhaled by the patient.

Of the properties needed in an anaesthetic there are three which can be closely related to chemical and physical properties. With especial reference to the work of Suckling (5). These are (a) absence of chemical toxicity, (b) absence of inflammability and explosive hazards, and $(c)$ anaesthetic potency.

Let us study first the problem of toxicity. One way of reducing the risks of toxicity is to work with compounds chemically inert, such as Fluothane and ether. Suckling proved that Fluothane and ether possessed a high degree of chemical stability. Analyses revealed that free acids and phosgene are not present in greater proportions than one part per ten million. Sirce purity of an anaesthetic must be over 99.95 per cent, the Fluothane-ether mixture with a purity over 99.99 per cent is certainly suitable. The mixture had been stabilized with thymol and kept in a brown bottle to prevent all decomposition by light. A bottle of this 
mixture was left at room temperature for four months, and no decomposition was observed: the azeotropic mixture remained stable.

Several experiments were carried out to prove that the Fluothane-ether anaesthetic was not inflammable in the azeotropic proportions in clinical uses. This mixture, made of 317 parts of ether and 68.3 parts Fluathane, was used in the Boyle apparatus.

The Fluotec and Stephen vaporizers were opened at different degrees and then at maximum, 4.4 per cent in volume, while a current of 100 per cent oxygen was circulated, and several vapour samples were recovered by means of a special apparatus resembling an electric bulb (Fig. 2). This bulb contained an electric filament and possessed two stopcocks: one was used to remove air, and the other, to receive gas samples.

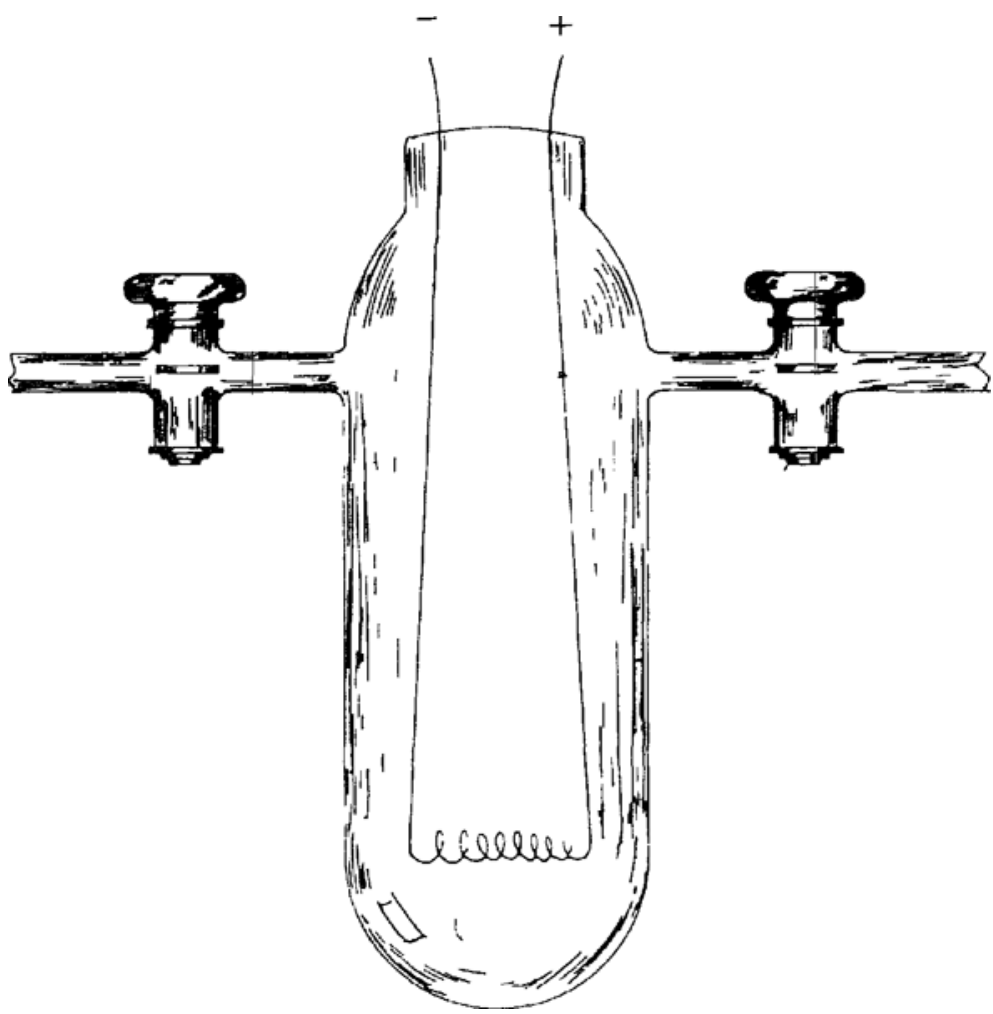

Figure 2. Container used to determune the gas inflammability. By means of two stopcocks it was possible to make a vacuum in the apparatus and to introduce gas samples. The wire's becoming incandescent permitted determination of the inflammability of the sample.

When electricity was turned on, it was found that vapours of this mixture were not inflammable: the bulb produced luminescence. The Fluothane, according to Seiflow (4), acts as an inert diluent when it is added to an inflammable mixture of ether and oxygen.

The azeotropic mixture was not found dangerous when mixed with oxygen in the percentage of 4.4 per cent by volume; however, it was of great interest to find the inflammability limits. For this purpose, a rubber balloon was used. 
The room temperature was $25^{\circ} \mathrm{C}$. and the atmospheric pressure of $741.4 \mathrm{~mm}$. $\mathrm{Hg}$. A volume of $4,000 \mathrm{cc}$. of oxygen measured with a rotameter was introduced into the air-free balloon and with a graduated syringe known quantities of the azeotropic mixture were added. To vaporize the azeotropic compound the balloon was heated at $52^{\circ} \mathrm{C}$. in a water bath. While this gaseous mixture was at a temperature of $52^{\circ} \mathrm{C}$., gas samples were taken by means of syringes. By inserting a match into the syringe, it was possible to observe if an explosion occurred. It was found that the azeotropic mixture may be mixed with oxygen in proportions of 10.7 per cent by volume without danger of explosion (Table I).

TABLE I

\begin{tabular}{|c|c|c|c|c|}
\hline \multirow{2}{*}{$\begin{array}{l}\mathrm{Az} \text { (cc) mixture } \\
\end{array}$} & \multicolumn{2}{|c|}{ Gas volume at $52^{\circ} \mathrm{C} .8741 .4 \mathrm{~mm} \mathrm{Hg}$} & \multirow{2}{*}{$\frac{\text { Az mixture }}{\text { Total mixture }}$} & \multirow[b]{2}{*}{ Explosivity } \\
\hline & Az mixture & Oxygen & & \\
\hline & (cc) & (cc) & $(\%)$ & \\
\hline 10 & 2611 & 43624 & 565 & - \\
\hline 12 & 3133 & 43624 & 670 & - \\
\hline 14 & 3655 & 43624 & 773 & - \\
\hline 16 & 4178 & 43624 & 874 & - \\
\hline 18 & 4700 & 43624 & 973 & - \\
\hline 20 & 5222 & 43624 & 107 & - \\
\hline 205 & 5353 & 43624 & 109 & + \\
\hline 21 & 5483 & 43624 & 112 & + \\
\hline
\end{tabular}

A mixture composed of 50 per cent Fluothane and 50 per cent ether was also vaporized in the Boyle apparatus opened at 3 per cent, not by means of a current of 100 per cent oxygen, but by one of 50 per cent cixygen and 50 per cent nitrous oxide. Samples were tested in our apparatus (Fig. 2) and it was observed there was no risk of inflammability.

After these experiments, is was of great interest to find inflammability limits of the mixture at the liquid stage. It was found that the security proportions should be 55 per cent Fluothane and not more than 45 per cent ether. To find these proportions different mixtures were prepared and tested with the flame of a Bunsen burner. It was observed that a mixture of 48 per cent ether and 52 per cent Fluothane did not inflame spontaneously but only after 5 or 6 seconds of contact with the flame.

If such a mixture of 45 per cent ether and 55 per cent Fluothane was administered drop by drop, a period of about 2 hours was necessary to use $200 \mathrm{cc}$. and the composition did not change by more than 0.2 per cent. However, when a bottle with an opening of about $0.5 \mathrm{in}$. in diameter and containing $200 \mathrm{cc}$. of the same mixture was left opened at room temperature, a period of at least two months was necessary to evaporate all the liquid (Table II). The last cubic centimetre analysed gave the azeotropic composition: 31.7 per cent ether and 68.3 per cent Fluothane.

No matter what the proportions in which Fluothane and ether are mixed, they will always tend to volatilize in azeotropic proportions. The risks of inflammability necessarily decrease because the Fluothane concentration increases when the ether proportion decreases. 
TABLE II

Vaporization at RoOM Temperature

\begin{tabular}{|c|c|c|}
\hline $\begin{array}{l}\text { Volume } \\
\text { (cc) }\end{array}$ & $\begin{array}{c}\text { Time } \\
\text { (weeks) }\end{array}$ & $\begin{array}{c}\text { Ether-Fluothane } \\
(\%)\end{array}$ \\
\hline 200 & & $\begin{array}{lll}49 & 0-51 & 0\end{array}$ \\
\hline 180 & 1 & $465-535$ \\
\hline 155 & 2 & $415-555$ \\
\hline 105 & 4 & 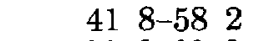 \\
\hline 85 & 5 & $\begin{array}{lll}39 & 2-60 & 8\end{array}$ \\
\hline 50 & 6 & $\begin{array}{lll}37 & 0-63 & 0\end{array}$ \\
\hline 28 & 7 & $\begin{array}{lll}33 & 0-67 & 0\end{array}$ \\
\hline 8 & 8 & $\begin{array}{llll}31 & 7-68 & 3\end{array}$ \\
\hline
\end{tabular}

The final problem was to choose compounds with adequate anaesthetic potency. Basing our researches on the work of Meyer and Hemmi (1), Mullins (2), and Robbins (3), we find that the anaesthetic potency of the azeotropic mixture was determined by the relative saturation of anaesthetic, which is given by the ratio of the partial pressure producing anaesthesia $(\mathrm{Pa})$ to the saturated vapour pressure of the compound $(P s)$ at the temperature of the experiment. At a temperature of $24^{\circ} \mathrm{C}$, the saturated. vapour pressure of the azeotropic mixture was determined and it was found equal to $213.3 \mathrm{~mm}$. Hg while the atmospheric pressure was $742 \mathrm{~mm}$. $\mathrm{Hg}$.

The partial pressure producing anaesthesia was calculated from Suckling's formula:

$$
\frac{\text { concentration of the mixture } \times \text { atmospheric pressure. }}{100}
$$

As the concentration used during anaesthesia was 1.5 per cent by volume, the partial pressure producing anaesthesia was equal to $11.13 \mathrm{~mm}$. $\mathrm{Hg}$.

In the ratio $\mathrm{Pa} / \mathrm{Ps}$ the relative saturation was equal to 0.052 while the Boyle apparatus was giving a normal volume flow of 1.5 volumes per cent.

In clinical use considering a non-toxic and non-inflammable compound as a good anaesthetic when it is administred at a relative saturation of 0.03 to 0.08 , it may be concluded that the Fluothane-ether azeotropic compound compares favourably with the best anaesthetics already known.

\section{REFERENCES}

1 Meyen, K. H, \& Hemmi, H. Bjochem. Z. 277: 39 (19:35).

2. Mullins, L. J. Ghem. Rev. 54:-289 (1954).

3. Robins, B. H. J. Pharmacol. 86: 197 (1946).

4. Seiflow, G. H. F. Brit. J. Anaesth. $29 \cdot 438$ (1957).

5. Suckinng, C. W. Brit. J. Anaesth. 29: 466 (1957). 